How We Do It.....

DOI: http://doi.org/10.4038/cjo.v8i1.5293

\title{
A protocol for management of Rhino-cerebral Mucormycosis.
}

\author{
Udayani LADN 1 , Daminda DADG ${ }^{2}$, Rupasinghe $\mathrm{RT}^{2}$ \\ ${ }^{1}$ Senior Registrar in ENT, Teaching Hospital Anuradhapura, Srilanka \\ ${ }^{2}$ Consultant ENT and Head \& Neck Surgeon, Teaching Hospital Anuradhapura, Srilanka
}

\section{Key Messages}

1. Rhino-orbital symptoms and sings in an immunocompromised patient along with fat stranding in CT scan are strongly suggestive of RCM.

2. Sinoscopy under anesthesia may be required for definitive diagnosis of RCM as nasal examination can be completely normal in early stages.

3. Liposomal Amphotericin along with other supportive measures and strict fluid/ electrolyte balance can reduce mortality significantly

4. Topical conventional Amphotericin packaging is an important adjunct to systemic therapy.

Keywords: Rhino-cerebral Mucormycosis, Mucormycosis, Fungal Sinusitis

Copyright: (C) 2020 Udayani LADN et al.

This is an open access article distributed under the Creative Commons Attribution License (CC-BY) CC) () , This license lets others distribute, remix, tweak, and build upon the work, even commercially, as long as they credit the original author for the creation.

Funding: None

Competing interest: None

Correspondence: Dr LADN Udayani (nadeejalad@gmail.com)

Accepted Date $: 6^{\text {th }}$ Feb 2020

Published Date : 22 $2^{\text {nd }}$ Feb 2020 


\section{Introduction}

Rhino-cerebral Mucormycosis (RCM) is an invasive fungal infection caused by filamentous fungi of the Mucoraceae family ${ }^{[1,2]}$. Majority caused by organisms in the genera Rhizopus (70\%), to a lesser extent by Lichthemia and Mucor and rarely by Rhisomucour, Apophysomyces and Saksenea ${ }^{[3,4]}$. The disease is commonly associated with an immunosuppressive state and most commonly seen amongst diabetic patients ${ }^{5}$.

RCM becomes common in Anuradhapura during rainy seasons and currently we are facing the worst epidemic experienced during last 5-6 years. RCM has a very high mortality rate which is typically more than $50 \%{ }^{5}$. A retrospective study carried out at teaching hospital Anuradhapura in 2018 (12 patients from 2015 -2017) has shown a mortality rate of more than $65 \%$ in spite of treatment. Therefore, we have taken some important steps to try and decrease mortality and come up with a departmental protocol. With this we have experienced a remarkably low mortality rates and we are yet to see any deaths managed using this protocol during this year (7 cases).

The key points of our departmental protocol are

1. Early diagnosis (clinical, radiological and laboratory)

2. Aggressive endoscopic debridement

3. Liposomal Amphotericin

4. Fluid, electrolyte balance and other supportive measures

5. Follow up endoscopic examination/debridement and topical treatment

\section{Early diagnosis}

Because of the relative low incidence of the invasive fungal sinusitis, a high index of suspicion must be maintained to arrive at an early diagnosis ${ }^{[6]}$. This is a key factor leading to a better prognosis. RCM usually presents with headache, retro-orbital/orbital pain, fever, nasal discharge, proptosis, ophthalmoplegia, loss of vision ${ }^{[6]}$. Our previous study showed that unilateral headache as the commonest presentation and most have developed multiple cranial nerve palsies during the course of the illness.

An urgent CT scan of nose paranasal sinuses with fine cuts will be carried out, sometimes even before endoscopic examination. Intravenous contrast is indicated whenever possible especially when intracranial or intra-orbital extension is suspected. Otherwise a non-contrast CT is adequate in most instances. Mild to moderated unilateral mucosal thickening is usually a common initial finding. Infiltration of peri-antral fat planes (fat standing) is an initial CT sign of invasive fungal sinusitis ${ }^{[7]}$. There may be focal bony erosions, air fluid levels, obstruction of osteo-meatal complex, heterogeneous opacifications with focal areas of high signal intensity. CT may be normal in about $12 \%$ especially when disease is limited to nasal cavity. ${ }^{[8]}$ 


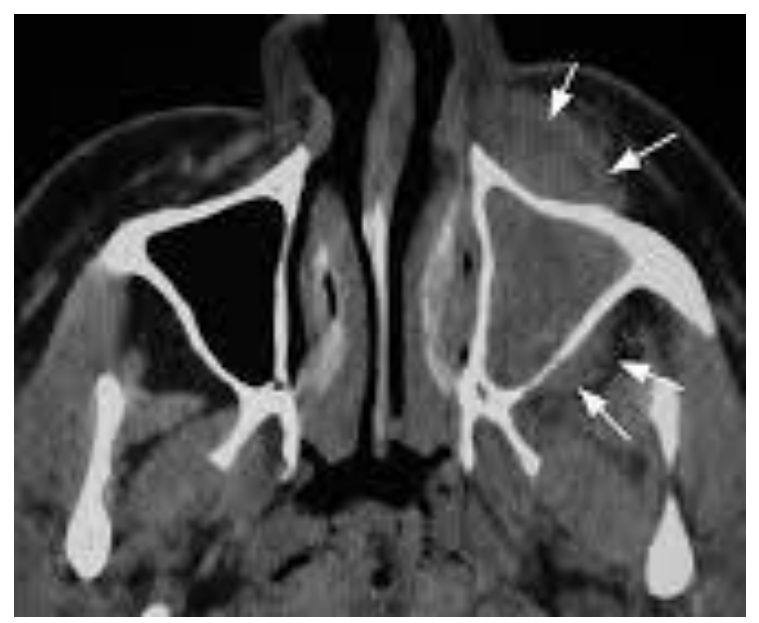

Fig1: Infiltration of peri-antral fat planes in CT

\section{Endoscopic examination and aggressive debridement}

Immunocompromised patients with localized sino-nasal and orbital symptoms are urgently examined at our department with nasal endoscopy to rule out RCM. Rigid nasal endoscopic evaluation may only show subtle changes or it can be normal initially. Therefore, we tend to do this under general anesthesia and keep a low threshold for sinostomies (middle meatal antrostomy and/or spheno-ethmoidectomy) depending on CT findings. Alteration in the appearance in the mucosa is the most striking feature. Normal typical pinkish appearance in nasal mucosa can be replaced by discoloration, ulceration or granulation. Angioinvasion will cause a tissue ischemia and mucosa will appear whitish, and later it will become blackish due to the tissue necrosis. Nowadays we see quite a number of patients with normal nasal mucosa but pale sinus walls on sinostomies. This is probably due to high index of clinical suspicion and early endoscopy.

Nasal mucosal abnormalities, when present, most commonly appear on middle turbinate $(67 \%)$, followed by septum $(24 \%)$, palate $(19 \%)$ and inferior turbinate $(10 \%)^{[8]}$. Reduced mucosal sensation and decreased mucosal bleeding can also be noted.

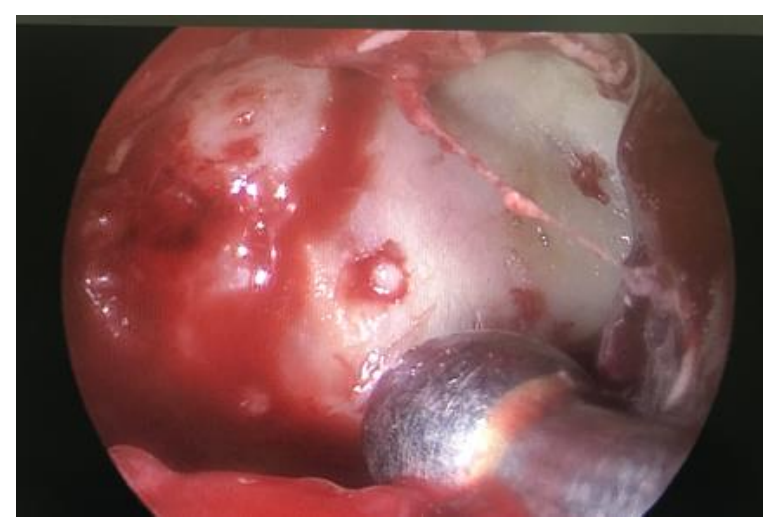

Fig 2: This pale sinus wall is seen only after an antrostomy and in this case nasal endoscopy was completely normal.

Aggressive surgical debridement of all necrotic tissue is done until normal well-perfused bleeding tissue edges are seen. Sometimes this requires entering into pterygopalatine fossa, infratemporal fossa or orbital decompression. We try to do maximum surgical debridement during the initial surgery. It reduces the fungal load and provide samples for fungal studies. Surgery can reduce and halt the progression of the disease. 
Samples are taken from suspicious areas for fungal studies, cultures and histology. We have established a system to transport samples urgently to Medical Research Institute, Colombo for urgent microscopic examination and cultures. Direct smear will demonstrate hyphal forms within the submucosa with or without angiocentric invasion in mucormycosis.

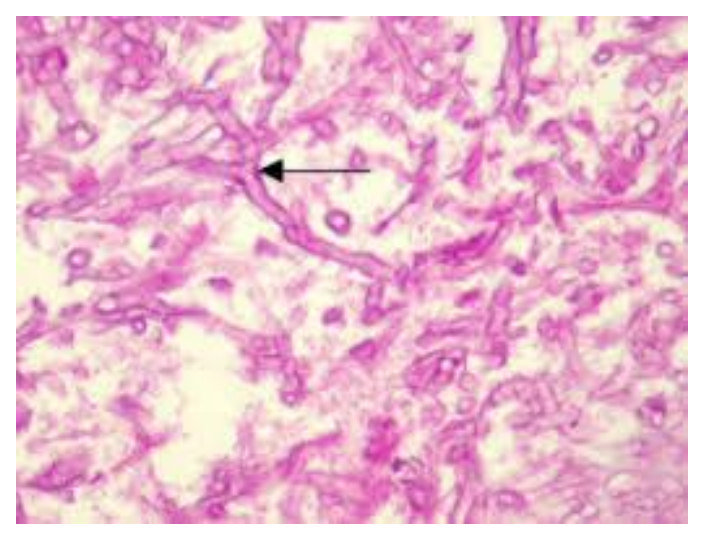

Fig 3: Zygomycosis fungi under microscopy

\section{Liposomal Amphotericin}

Amphotericin B is the drug of choice for this disease. However, unfortunately we have experienced serious side effects including deaths with conventional Amphotericin B. Even though Liposomal Amphotericin B is significantly more expensive compared to conventional form we have experienced significantly low side effect profile and very good response to treatment. This fact is well established in the literature. ${ }^{[9]}$

We emphatically start intravenous liposomal Amphotericin B on clinical suspicion. Baseline renal functions and liver functions are done prior to starting Amphotericin. The standard dose is $3 \mathrm{mg} / \mathrm{Kg}$ bodyweight ${ }^{[10]}$ after a test dose. However, 2013 ESCMID and ECMM (European Society for Clinical Microbiology and Infectious Diseases and European Confederation of Medical Oncology) joint clinical guidelines for the diagnosis and management of mucormycosis recommends $5 \mathrm{mg} / \mathrm{kg}$ body weight except when CNS involvement is present ${ }^{[11]}$. However, a dose of $3 \mathrm{mg} / \mathrm{kg}$ appears to be is adequate for our patients, especially in the context of significant financial burden to the health care system.

According to the literature, usual recommendation is to give a total accumulated dose of 2.5 to $3 \mathrm{~g}$ of Amphotericin B. However, there are some reports of loading 5-6g ${ }^{[12]}$. We usually give Liposomal amphotericin for total duration of 4-6weeks depending on the severity of the case. This means we load a total of $4.2-6.3 \mathrm{~g}$ of Amphoteracin into our patients. Our patients appear to tolerate this regimen very well and we will be reporting a case series to determine its long-term outcome

Conventional Amphotericin B is used only when Liposomal form is not available. After a test dose conventional form is given by a gradually increasing dosage and given at a dose of $1 \mathrm{mg} \mathrm{kg} \mathrm{BW}$. It is not recommended to be increased to more than $1.5 \mathrm{mg} / \mathrm{Kg}$ due to its side effects, especially the risk of sudden cardio- respiratory events.

We routinely obtain nephrology opinion when serum creatinine goes up and sometimes Amphotericin is temporarily withheld when serum creatinine doubles from the baseline value. There are concurrent bacterial infections and relevant intra venous antibiotics are given during initial period. 


\section{Fluid, electrolyte balance and other supportive measures}

Hydration with normal saline is done before and after the Amphotericin infusion- usually $250 \mathrm{ml}$ is infused before and after. Strict Fluid balance charts are maintained and about 2500-3000 $\mathrm{ml}$ of fluid intake is maintained. Serum Creatinine and serum electrolytes are done daily afterwards. CRP, FBC, serum Magnesium, serum calcium is done about every other day. Serum phosphate is done about very $5^{\text {th }}$ day. Electrolyte abnormalities (hypokalemia, hypocalcemia and hypomagnesaemia) are common with amphotericin due to renal tubular acidosis. Electrolyte abnormalities are treated accordingly and investigations need to be done more frequently when they are low.

Tight glycemic control is achieved using insulin and help of the endocrinologist sought early. Any other immunosuppressive states are also addressed. Nutrition levels of these patients are optimized with the help of nutritionist.

\section{Follow up endoscopic examinations and topical treatment}

Rigid nasal endoscopic examinations are done about twice a week. Debridement of necrotic materials mostly done under local anesthesia and sometimes under general anesthesia. We tend to limit aggressive debridement procedures under general anesthesia when electrolyte abnormalities are present. Other than intravenous Amphotericin, we carry out local packing of the sinuses and nasal cavity with conventional Amphotericin B soaked nasal packs every third day. We have also been trying douching and irrigation with conventional Amphotericin to give some packing free intervals.

After the completion of 4-6 weeks' treatment we perform a follow up CT to exclude any progression and repeat samples are sent for fungal studies to exclude any active infection. These along with endoscopic finding and CRP levels are used to make a decision to stop treatment. However, we closely monitor them inward for about a week even after stopping treatment. This is because half-life of Amphotericin increases with long term use. Then we review them weekly with RNE for about a month then interval is increased.

\section{Conclusion}

We can achieve a remarkably low mortality in patients with RCM with early diagnosis, aggressive surgical debridement, liposomal amphotericin, topical Amphotericin therapy, control of underlying comorbidities and other supportive measure with close monitoring. High index of suspicion must be maintained in atrisk populations, in order to rapidly execute a multifaceted approach. 


\section{Departmental Protocol for management of Rhino-cerebral Mucormycosis}

- Urgent CT and RNE

- Aggressive surgical debridement and sent samples for direct smear, culture \& histology

- Start IV Liposomal Amphotericin B - 3mg / Kg BW daily after test dose as soon as possible. Can increase up to $5 \mathrm{mg} / \mathrm{Kg}$ BW

(Reconstitute the Amphotericin vial strictly according to manufactures advices)

- Hydrate with $250 \mathrm{ml}$ of normal saline before and after IV amphotericin.

- IV Ceftazidime, or relevant IV antibiotic.

- Baseline renal function and liver functions

- Daily serum creatinine and serum electrolytes.

- $\quad$ CRP, FBC, serum Magnesium, serum Calcium, BU every other day, serum Phosphate every $5^{\text {th }}$ day.

- Correct electrolyte abnormalities accordingly \& repeat Ix more frequently if they are abnormal

- Maintain daily IP/OP chart.

- When serum creatinine level doubles Amphotericin is usually withheld until it becomes to baseline value.

- Maintain tight glycemic control.

- Frequent RNE and debridements of necrotic tissue

- Local packing with Amphotericin packs every third day 


\section{References}

1. Gunasekara GCS, Patabandige CGUA, Jayasekara PI, Dayasena RP, Rhinocerebral mucormycosis : a case report; Srilankan Journal of infectious disease ,2016;6;(1);67-70

https://doi.org/10.4038/sljid.v6i1.8100

2. Hong HL, Lee YM, Lee SO;Risk Factors for Mortality in Patients with Invasive Mucormycosis Infect Chemother, 2013 Sep; 45(3): 292-298

https://doi.org/10.3947/ic.2013.45.3.292

PMid:24396630 PMCid:PMC3848522

3. Petriko G, Skiada A, Lortholary O, Epidemiology and clinical manifestations of Mucomycosis, Clin infect Dis ;2012 Feb;54 Suppl 1: S23-34. doi: 10.1093/cid/cir866

https://doi.org/10.1093/cid/cir866

PMid:22247442

4. Prakash H, Chakrabarti A; Review Global Epidemiology of Mucormycosis; Journal of Fungi 2019, 5, 26;

doi:10.3390/jof5010026

https://doi.org/10.3390/jof5010026

PMid:30901907 PMCid:PMC6462913

5. Rodrigo C, Lemarroy C, Irineo E, Moreno G, Gutiérrez RR, et al., Clinical Features and Outcome of Mucormycosis, Interdisciplinary Perspectives on Infectious Diseases, vol. 2014, Article ID 562610, 5 pages, 2014. https://doi.org/10.1155/2014/562610 PMid:25210515 PMCid:PMC4158140

6. Palejwala SK, Zangeneh TT, Goldstein SA, Lemole GM. An aggressive multidisciplinary approach reduces mortality in rhinocerebralmucormycosis, Surg Neurol Int ,25-May-2016; 7:61

https://doi.org/10.4103/2152-7806.182964

PMid:27280057 PMCid:PMC4882964

7. Epstein V.A; Kern R.C.; Invasive Fungal sinusitis and complication of Rhinosinusitis; The otolaryngology clinics of North America; Volume 41; 2008; page 497-524

https://doi.org/10.1016/j.otc.2008.01.001

PMid:18435995

8. Gillespie M.B; O'Malley B.W; An Algorithmic approach to the diagnosis and management of invasive fungal sinusitis in the immunocompromissed patient; The Otolaryngology clinics of North America; Volume 33; Number 2; April 2000; Page 323-334

https://doi.org/10.1016/S0030-6665(00)80008-0

9. Walsh TJ et al, Liposomal amphotericin B for empirical therapy in patients with persistent fever and neutropenia, National Institute of Allergy and Infectious Diseases Mycoses Study Group,NEngl J Med; 1999; 340:764-771 March 1999.

https://doi.org/10.1056/NEJM199903113401004

PMid:10072411

10. Moen MD, Lyseng-Williamson KA, Scott LJ;Liposomal amphotericin B: a review of its use as empirical therapy in febrile neutropenia and in the treatment of invasive fungal infection. Drugs. 2009;69(3):361-92.

https://doi.org/10.2165/00003495-200969030-00010

PMid:19275278

11. Cornely OA et al. ESCMID and ECMM joint clinical guidelines for the diagnosis and management of mucormycosis 2013

Clin Microbiol Infect. 2014 Apr;20 Suppl 3:5-26. doi: 10.1111/1469-0691.12371.

https://doi.org/10.1111/1469-0691.12371

PMid:24479848

12. Handzel, Landau Z, Halperin D; Liposomal amphotericin B treatment for rhinocerebral mucormycosis: How much is enough? Rhinology, 41, 184-186, 2003 